Article

\title{
Regenerative Development as an Integrative Paradigm and Methodology for Landscape Sustainability
}

\author{
Leah V. Gibbons ${ }^{1, *}$, Scott A. Cloutier ${ }^{2}{ }^{(D}$, Paul J. Coseo ${ }^{3}$ and Ahmed Barakat ${ }^{1}$ \\ 1 School of Sustainability, Arizona State University, Tempe, AZ 85287, USA; aabarakat@gmail.com \\ 2 School of Sustainability, Julie Ann Wrigley Global Institute of Sustainability, Arizona State University, \\ Tempe, AZ 85287, USA; scott.cloutier@asu.edu \\ 3 The Design School, Herberger Institute for Design and the Arts, Julie Ann Wrigley Global Institute of \\ Sustainability, Arizona State University, Tempe, AZ 85287, USA; paul.coseo@asu.edu \\ * Correspondence: leah.gibbons@asu.edu
}

Received: 1 April 2018; Accepted: 5 June 2018; Published: 7 June 2018

\begin{abstract}
Although the integration of sustainability, ecology, and design has been recognized as necessary by scientists and practitioners, most transdisciplinary frameworks are not inclusive of the worldviews, paradigms, aims, processes, and components necessary for sustainability. Landscape sustainability science helps to focus scientist, scholar, practitioner, and stakeholder efforts toward sustainability at a pivotal level; however, collaboration and progress have been slow. Significant potential exists for design to be an integrative and transformational methodology toward landscape sustainability, yet it has not fulfilled this ambitious role. In this paper, we first build a case for regenerative development, a development and design methodology based on an ecological worldview, as an integrative platform for a new paradigm. This new paradigm, which we call regenerative landscape development, has the potential to thoroughly catalyze a shift toward regenerative sustainability. We then detail this new paradigm as a process that could continually enhance the capacities of living systems to increase health, well-being, and happiness. Next, to illustrate regenerative development in practice, we provide brief case studies of projects in Viña del Mar, Chile and Juluchuca, Guerrero, Mexico. Finally, we propose future recommendations and precautions in the construction of regenerative landscape development as a new paradigm. If fully understood, embraced, and realized, regenerative development holds incredible potential for a sustainable future.
\end{abstract}

Keywords: regenerative development; sustainable development; landscape sustainability science; ecological design; ecological planning; urban design; urban planning; landscape design; landscape planning; social-ecological systems

\section{Introduction}

In terms of the goal of sustainability in landscapes, landscape sustainability science calls for "a place-based, use-inspired science of understanding and improving the dynamic relationship between ecosystem services and human well-being with spatially explicit methods" [1]. Landscape sustainability science is heavily influenced by landscape ecology; it also recognizes the social significance of landscapes as the scale at which the inhabitants of a place most directly affect and connect with the land and each other [1-3]. As social-ecological systems, landscapes are widely recognized as the foundation of critical life systems and a pivotal focal scale for sustainability efforts $[1,4,5]$. In addition, landscapes are where scientists and practitioners blend natural and 
social scientific knowledge and practice [6]. Yet, landscape sustainability science has not provided holistic guidance for the transformational regeneration of multi-scalar landscapes. Scientists, scholars, practitioners, and stakeholders still struggle to collaborate in impactful and transformative ways toward sustainable processes and outcomes.

Design, as well as its social and biophysical outcomes, holds potential as an important, integrative, and transformational methodology for sustainability in landscapes [7-11]. Here, we use "design" as an inclusive term which refers to the disciplines of design (landscape architecture, architecture, urban design, engineering) as well as both the planning and final manifestation into physical and social realities. We use "methodology" as the underlying rationale for conducting and structuring both research and practice, including more specific methods, processes, and tools. The potential of design to synthesize descriptive, analytical, and transformational modes of sustainability science in landscapes has not been fully recognized or utilized by scientists or practitioners. Even within its domain, design seldom addresses root causes of sustainability challenges or the necessary capacities for social-ecological systems to evolve continually so that sustainability, as a process that occurs throughout time, can unfold. Regenerative development, an emerging design and development approach that shifts the focus from solving problems to manifesting potential in living systems, has the capacity to fill these gaps.

We propose regenerative development as a means of transforming current landscape sustainability theory and practice. To do so, regenerative development should fully integrate landscape sustainability science and design to reach its potential as a transformational sustainability approach. We discuss design as an integrative and transformational methodology for sustainability. Next, we explore gaps in the integration of sustainability, ecology, and design as well as the potential of regenerative development to serve as an integrating platform for a new paradigm, namely, regenerative landscape development. We illustrate two case studies that embody regenerative development practices as a means of promoting similar efforts in the future. Finally, we conclude with recommendations for advancing regenerative landscape development as a paradigm.

\section{Design as an Integrative Transformational Methodology}

Design holds unrealized promise in making transformational progress towards sustainability [7,12-14]. Broadly, design is "the purpose, planning, or intention that exists, or is thought to exist, behind any action or object" [7] (p. 3775). In landscapes, design manifests underlying societal worldviews, values, and knowledge as landscape use and change. It contributes most of the environmental impacts of the built environment [6,15]. Further, design influences people's beliefs, values, and actions, which can become more or less sustainably oriented and result in the propagation of those new beliefs, values, and actions [16-20].

Western-derived design approaches dominate the design and planning of urban systems around the globe, from Shanghai to Dubai. These western contemporary design approaches have evolved over the past 150 years from 'designer as artist' (e.g., Georges-Eugène Haussmann) [21] to 'designer as technocrat' (e.g., Le Corbusier) [22] to 'designer as facilitator' (e.g., Judith E. Innes) [23]. Design and planning moved toward facilitating participatory social learning processes to address the failures of the technocratic, mechanistic approaches of the $20^{\text {th }}$ century. The massive failures of urban renewal efforts in many western cities served as a transformational catalyst for the design disciplines. The strength of current design best practices is that such disciplines have begun to describe place-based, contextual, participatory, and deliberative social learning processes which better integrate diverse knowledge and values from social and ecological worlds [24]. However, it is naïve to think "expert-driven" approaches do not continue to dominate our approach to design. Design has not exorcised many of its technocratic, mechanistic, and "expert-driven" tendencies. Today, we are left with a complex portfolio of design approaches as a result of these three models of design. At the beginning of the 21st century, we still see the simultaneous use of all three design approaches in complex and problematic ways for social-ecological systems. 
The worldviews according to which design is practiced are critical. Landscape design is still largely based on mechanistic worldviews and reductionist paradigms that prevail in western society, both of which attempt to dominate and control nature and society for human benefit [24-26]. Importantly, modern design is predominantly practiced in a fragmented way. Design processes and outcomes tend to focus solely on one or more components rather than the whole system. They largely divorce practitioners from residents, researchers from practitioners, residents from researchers, and, ultimately, people from natural processes. When practiced from such a mindset, design processes and outcomes perpetuate the thinking, practices, products, and lifestyles that underlie and result in unsustainability $[19,26-28]$. Recently, the field of ecological design has intentionally shifted its worldview and paradigm to one that is more holistic in approach, one which more accurately reflects how nature works and provides healthier patterns of relationships between humans and between humans and nature. When practiced from an ecological worldview, design has the potential to shift thinking, practices, and lifestyles to more sustainable ones [19,26,28-33].

An ecological worldview inherently calls on design to integrate scientific, social, cultural, and metaphysical perspectives, knowledge, and intentions in artefacts, institutions, and processes that promote the sustainability of landscapes [18,19,31,33-36]. Henceforth, we will refer to this approach as regenerative design, which can change current conditions to more sustainable ones by utilizing systems thinking and abductive logic. Such an approach synthesizes patterns and understands the nature of complex systems; specifically, how to interact with them in ways that promote the regeneration of living systems $[10,26,29,33,37]$. Regenerative design can both respond to and transform values and belief systems on a scale that ranges from individuals to society; such systems are the basis of human-human and human-nature relationships and are the ultimate drivers of (un)sustainability [17,24,26,28,29,38-42]. Further, regenerative design can integrate descriptive, analytical, and transformational sustainability research and practice; simultaneously, it can be used as a platform for constructing and testing sustainability hypotheses $[1,7,8,43]$. When understood in this way, design can be used as a methodology to transform landscapes to both sustainable and thriving living systems (Figure 1).

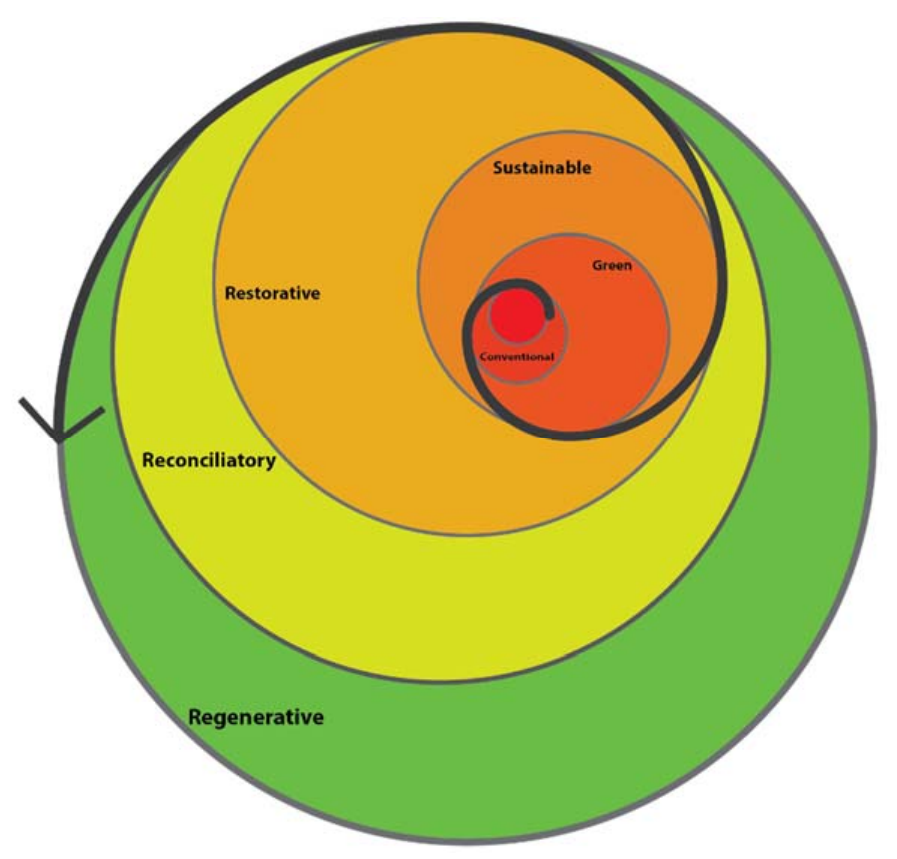

Figure 1. Cont. 


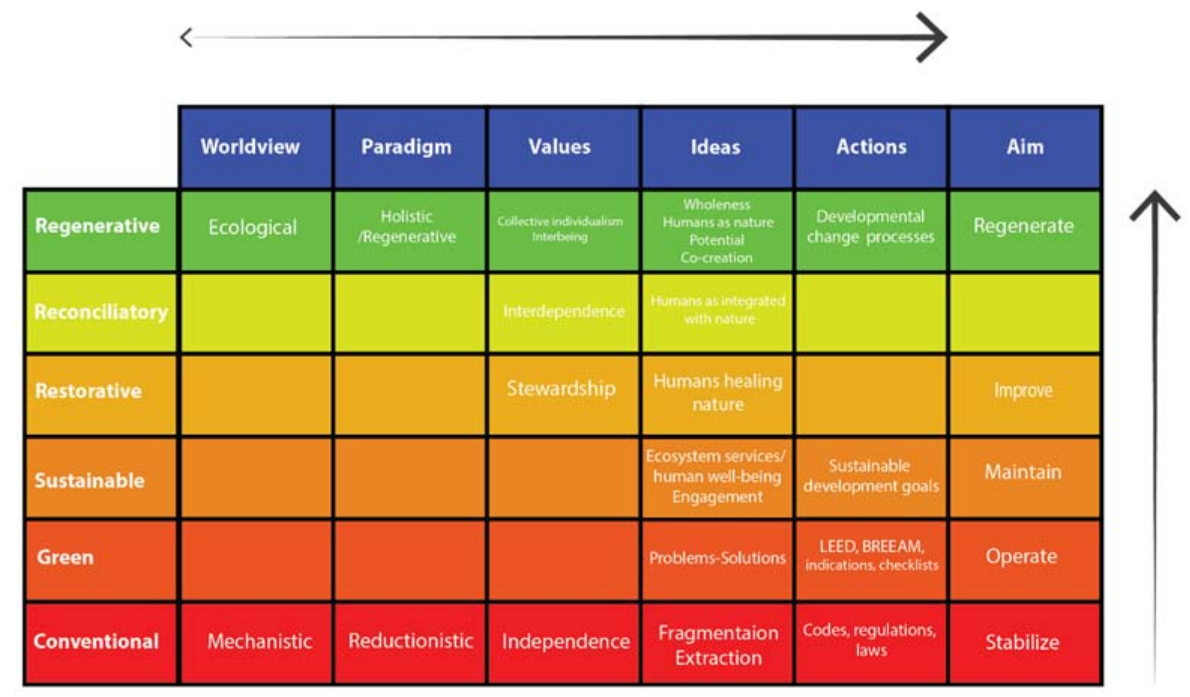

Figure 1. The spectrum from conventional to regenerative development and design methodologies. Each methodology builds upon and incorporates the last in an ascending spiral, representing an evolution from simple to more complex and inclusive ways of being and interacting in the world. The arrows in both the spiral and to the right of the chart show the direction of this evolution. The properties of lower methodologies are inherently present and available in upper methodologies, if needed. Further, each level is based upon a supporting worldview and paradigm, out of which specific values, ideas, levels of work, and actions develop. These properties influence one another to varying degrees, with worldviews exerting the strongest influence, as the arrow across the top indicates. The integration of all methodologies can result in a regenerative process to create whole, thriving, and healthy living systems.

\section{Integrating Sustainability, Ecology, and Design}

Sustainability scientists, practitioners, ecologists, and designers increasingly recognize the demand to co-create more sustainable social-ecological systems [1,3,5-7,11,31,35,40,44-50]. It is imperative that ecological and sustainability theory and knowledge be integrated with design [29,51]. Some transdisciplinary frameworks have been suggested to integrate ecology with design, ecology with certain aspects of sustainability, and design with the principles of ecology and sustainability $[7,40,44,45,47]$. However, most are lacking the adequate integration of necessary aspects of sustainability, ecology, and design, which include ecological, sociocultural, and spiritual dimensions. Further, they fail to acknowledge the complexity, health, and beauty of natural systems.

Although current frameworks are useful first attempts of transdisciplinary methodologies to incorporate science and practice for change toward sustainability, they do not adequately address several key components of sustainability of landscapes. We suggest that a design and development framework which integrates sustainability, ecology, and design would address these deficiencies by (1) fostering the necessary transformational changes in worldviews, values, and beliefs that underlie our physical world; (2) creating and nurturing the coupled ecological and sociocultural [ecocultural] relationships that are imperative for sustainable societies; (3) setting in motion processes which can continually improve the viability, vitality, and evolutionary capacity of social-ecological systems across the board so that they can evolve towards their highest potential; and (4) working synergistically on multiple scales to create and implement effective locally appropriate interventions and strategies within larger social-ecological system contexts while coordinating and leveraging such efforts on larger landscape (i.e., regional) scales $[1,26,36,42,43,52-55]$. We suggest that regenerative development can support a paradigm shift in which principles of landscape sustainability science and design are not separate. Rather, they can work together as part and parcel of one overarching paradigm, science, and practice to enhance the health and well-being of all members of a system. 


\section{Regenerative Landscape Sustainability: A New Paradigm?}

Regenerative development is a developmental change methodology, which has been in use for over 20 years [19]. It is based on ecological principles and an ecological worldview that consciously adopts a whole living systems approach and works towards regenerative sustainability [36]. Regenerative sustainability focuses on strengthening "the health, adaptive capacity, and evolutionary potential of the fully integrated global social-ecological system so that it can continue regenerating itself, thereby creating the conditions for a thriving and abundant future-not only for the human species, but for all life" [25] (p. 59). Regenerative development translates regenerative sustainability principles and values of wholeness, change, and interrelationship into design and development frameworks and technologies that create and manifest designs, plans, and capacities in social-ecological systems. The aim is to increase continually the well-being and manifest potential of whole systems as well as the systems in which they are nested through co-evolving mutualism $[18,26,36,56]$. Potential lies in the possible inherent future states of being for a system that are useful and value-adding to the larger systems of which it is a part. This goal is nothing less than catalyzing the transformation of social-ecological systems across scales into regeneratively sustainable states $[18,19,36]$. This differs from other sustainable design and development approaches and conceptualizations, the attitudes of which are anthropogenic, fragmented, prescriptive; such approaches and conceptualizations focus on the symptoms of unsustainability and aim for, among other things, incremental improvements, doing less harm, mitigating damage, or managing both humans and nature $[25,56,57]$.

It is useful to distinguish between regenerative development and regenerative design, which are distinct but necessary corollaries. While regenerative development determines the correct phenomena to give form to and build regenerative capacities in systems, providing a framework to guide actions (e.g., growing regenerative capacity of place-based social and physical interrelationships through regenerating life-giving flows of water), regenerative design applies a system of technologies and strategies rooted in an understanding of the inner workings of living systems to generate healthier life-promoting patterns in a place between social and biophysical components (e.g., a network of public-private partnerships supporting connected place-based technologies such as green roofs, bioswales, and constructed wetlands) $[36,46,56,58,59]$. Familiar regenerative design technologies include biophilic design, permaculture, biomimicry, and the Living Building and Community Challenges [58]. Regenerative design has often been practiced apart from a guiding regenerative development process. In these situations, design strategies will regenerate life processes on the sites where they are implemented, but they will not contribute to larger developmental change processes that perpetuate regenerative sustainability throughout a living system. Regenerative development is necessary to catalyze a systemic shift toward regenerative sustainability and includes appropriate regenerative design technologies and strategies [18,56,58].

Regenerative development and landscape sustainability science stem from the same natural and social science principles which characterize social-ecological systems: complex adaptive systems, self-organization, emergent properties, resilience, adaptive capacity, heterogeneity, diversity, tipping points, synergies, constant change, scale:pattern:process:design relationships, multi-scale networks, connectivity, and the constant exchange of materials and energy between and within systems. Both are concerned with stakeholder engagement, transdisciplinarity, as well as engagement across scales both in the landscape and at the local level while coordinating efforts at bioregional levels $[1-3,60]$. Both hold the improvement of human well-being and ecosystem functions and services as a goal while connecting people to place [1]. Grounded in design and development methodologies, regenerative development translates and operationalizes abstract ecological and sustainability concepts and principles into finer-scaled concepts useful to designers. For example, it provides guiding principles, frameworks, and technologies with which designers can work. Regenerative development bridges the sustainability-ecology-design gap via strengths and uniqueness where other transdisciplinary frameworks fall short.

Regenerative development: 
1. Manifests potential.

Regenerative development enhances regenerative capacity-viability, vitality, and evolutionary capacity-in living systems that manifests increasingly higher levels of health and potential. In other words, regenerative development focuses on positive outcomes for all members of a system, which inherently means increased opportunities for health, well-being, and happiness.

2. Shifts worldviews.

Regenerative development explicitly and deeply engages stakeholders, inhabitants of a place, and practitioners in a collaborative, co-creative process. This process shifts worldviews to ecological ones and, as a result, shifts values, beliefs, behaviors, and their sociocultural and physical manifestations (e.g., infrastructure) to ones that nurture thriving living systems.

3. Creates mutually beneficial, co-evolving relationships.

Regenerative development forms mutualistic relationships amongst the sociocultural and ecological components of systems that evolve through time.

4. Adds value across scales.

Regenerative development works explicitly across scales, at least one scale below and two scales above the focal project. It seeks to add integral, life-conducive value to systems. Smaller-scale (e.g., individual and local) efforts are coordinated within larger scale (e.g., regional) efforts and are leveraged to catalyze transformation toward sustainability throughout the living system.

5. Grows regenerative capacity in whole systems.

Regenerative development works with whole living systems, not just isolated fragments, to understand geological, ecological, and sociocultural relationships and flows to increase viability, vitality, and evolutionary capacity (i.e., regenerative capacity) $[18,19,36]$.

Further, regenerative development uses a variety of specific methods, techniques, and technologies that are locally adapted to achieve its overarching goals of creating regenerative capacity and manifesting ever-increasing potential. These include many accepted approaches, such as multifunctional landscapes, design experiments, safe-to-fail experiments, adaptive design, parametric design, biomimicry, biophilia, and permaculture. It also uses technologies specific to regenerative development, such as Living Systems Thinking, Story of Place, and Integral Assessment [2,3,7,18,19,36,43,45,56,59].

In addition to ecological and sociocultural components of the built environment (i.e., any environment in which humans are making alterations), regenerative development can be used for institutions, organizations, and human ecology $[18,19]$. For this reason, it has gained global attention from practitioners, scientists, governments, and non-profit organizations as a large-scale solution to sustainability problems. The Web of Science (4 May 2018) reports that, over the last several years, the sum of citations per year for articles about regenerative development has risen from two citations in 2008 to 105 in 2017, with 336 total citations (Figure 2). Enrollment in regenerative development training courses is also rising [61,62]. Special issues devoted to the subject are appearing more frequently in scientific journals (e.g., Building Research and Information, Journal of Cleaner Production). The British Commonwealth is committed to implementing regenerative development as its main strategy to combat climate change [63]. The World Future Council even has a regenerative cities initiative [64]. As one regenerative development leader recently stated, "regenerative development" is the new meme [62].

Regenerative development is poised to become a major force in the transformation of social-ecological systems toward sustainability. However, it needs conceptual and practical strengthening to fulfill this ambitious role. The inherent complexity of large-scale social-ecological systems, such as landscapes, requires multiple disciplines, practitioners, and stakeholders to effectively understand, envision, and enact transformational change towards regenerative sustainability. Current regenerative development frameworks, including those developed by Regenesis Group and the LENSES framework, are not specific for landscapes [18,65]. By fully integrating knowledge and practices from landscape sustainability science and design, regenerative development could transform 
into a new paradigm for research and action, known as regenerative landscape development, which can answer this call.

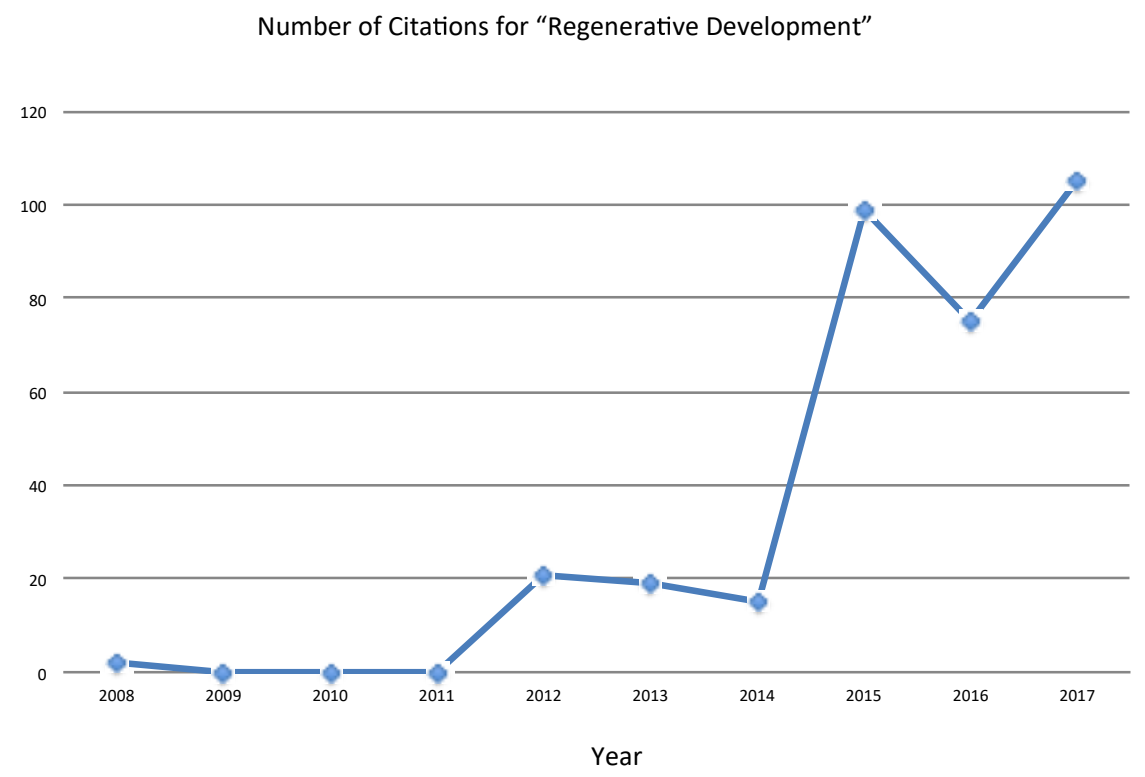

Figure 2. Number of citations per year for articles about regenerative development. Data retrieved from Web of Science, 4 May 2018.

In constructing a new paradigm, regenerative development offers landscape sustainability science a worldview, frameworks, methodologies, technologies, and methods to operationalize many of its principles. Landscape sustainability science offers regenerative development scientific frameworks, methodologies, tools, methods, and knowledge that can enable regenerative development to be rigorously and effectively applied at large scales. It can also aid in monitoring the impacts and outcomes of regenerative development projects, short-term and long-term, adjusting when necessary, and conducting valuable research to help improve sustainability outcomes through regenerative development. Regenerative landscape development as a new paradigm and methodology could unite sustainability, ecology subdisciplines, and design into one coherent field that overcomes the challenges typically encountered in interdisciplinary and transdisciplinary work; it could also affect significant transformational sustainability change from local to global scales.

\section{Case Studies}

The following case studies illustrate regenerative development theory and practice at landscape scales. They integrate ecology, design, and sustainability within a regenerative development framework to create regenerative capacity and move towards regenerative sustainability. They illustrate how regenerative development translates ecology and sustainability principles into practical applications for developmental change processes.

\subsection{Las Salinas Project, Viña del Mar, Chile}

Las Salinas is a 40-acre brownfield site located in Viña del Mar, Chile (Figure 3). It is owned by the Chilean energy company, COPEC SA, and has been used as a petroleum fuel distribution site for decades. In 2015, COPEC SA created a detailed redevelopment plan that maximized the development allowed there and presented it to the city as a "gift". This plan faced fierce backlash from the community, who feared it would bring similar problems that had overwhelmed the community in recent decades, namely, increased traffic congestion, decreased quality of life, and decreased agricultural yields [66]. The company decided to shift from a transactional approach to a reciprocal one. It enlisted Regenesis 
Group, a regenerative development consulting firm, to facilitate a collaborative relationship and regenerative development project with the Viña del Mar community [67]. Las Salinas embodies the progression from conventional to green to restorative to regenerative methodologies and the collective integration of each stage. It also demonstrates how a specific site can play a catalyzing regenerative role in the landscape (Box 1).

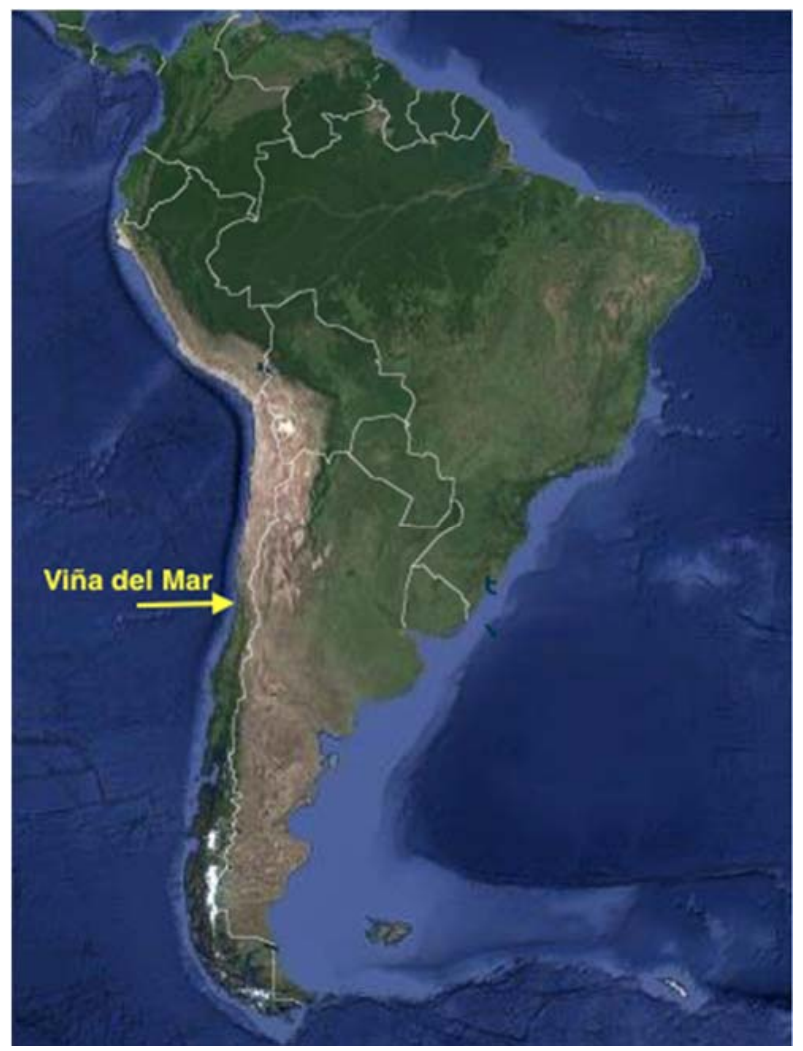

(a)

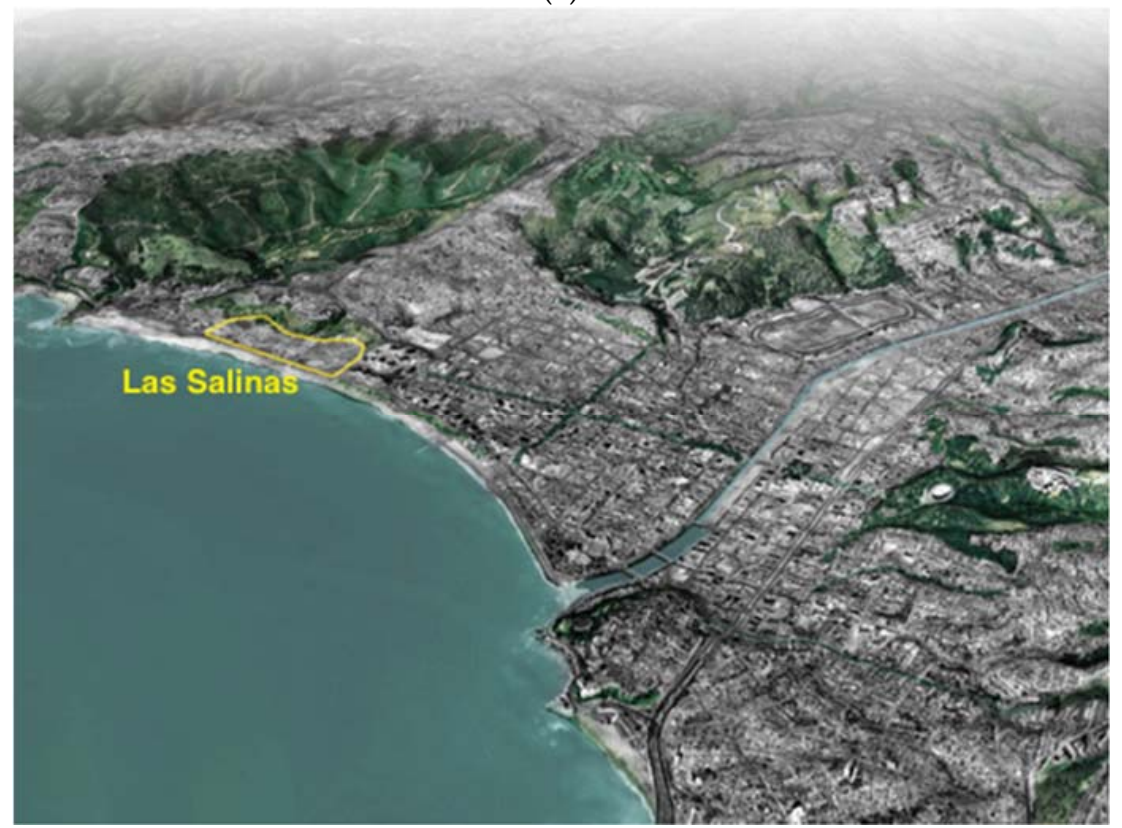

(b)

Figure 3. (a) Viña del Mar, Chile. Image adapted from Google Maps. (b) Las Salinas project location, Viña del Mar, Chile. Image adapted from Regenesis Group. 
The design team conducted a detailed integral assessment considering geological, ecological, and human components of the living system as well as their interactions through time and space. They also conducted deep listening sessions with the community, who was considered part of the design team. They connected to a feel of nostalgia for the Viña del Mar of the past, which exemplified its moniker, "Garden City" [66,67]. Viña del Mar, which translates to "Vineyard of the Sea", was a place associated with gentility, abundance, diversity, social and ecological connectivity, beauty and vitality; these community elements had degenerated over the last several decades. Las Salinas sits between what was a biodiverse hillside and the sea-an important connective element in the landscape. The regenerative development concept that emerged was to co-create Las Salinas as a connecting place and hub for the regeneration of the social and ecological components of Viña del Mar and the region beyond [66].

Eight bridging concepts emerged for the site design, which directly and indirectly connect the following biogeophysical and social elements of the city: habitat connection, estuary health, mobility, meaningful public space, cultural centers, community centers, marketplace, food networks, and youth education [67]. The site design proposes an ecosystem regeneration on the hillside which connects Las Salinas to a greater ecological context via its streets (which function as ecological corridors), green roofs, courtyards (which function as ecological patches or stepping stones), and linear parks that offer diffused connectivity throughout the space (Figure 4) [68]. Seascape views are preserved; an elevator takes people from the hillside to sea level, reengaging the community with its seafront and public spaces. A fully accessible and interconnected public realm network promotes greater social integration (Figure 5). In all, 4.5 billion square feet have been allocated for mixed-use LEED-ND certified development [66,67].

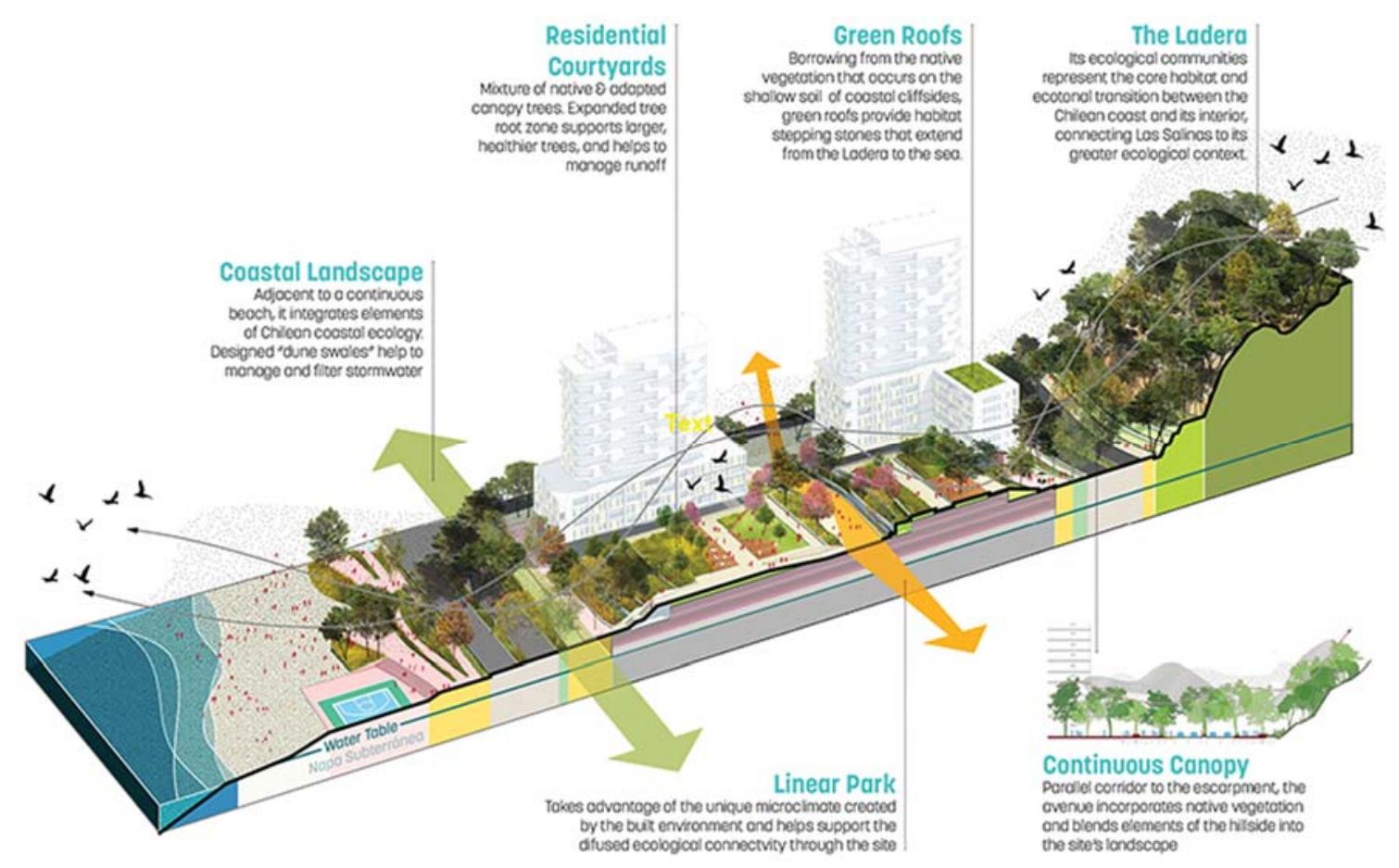

Figure 4. Las Salinas site plan facilitating ecological connectivity. Hillside ecosystem regeneration connects the site to its larger regional context. Streets function as ecological corridors, green roofs and courtyards as ecological patches, and linear parks as diffused connectivity elements throughout the site. Image courtesy of Sasaki. 


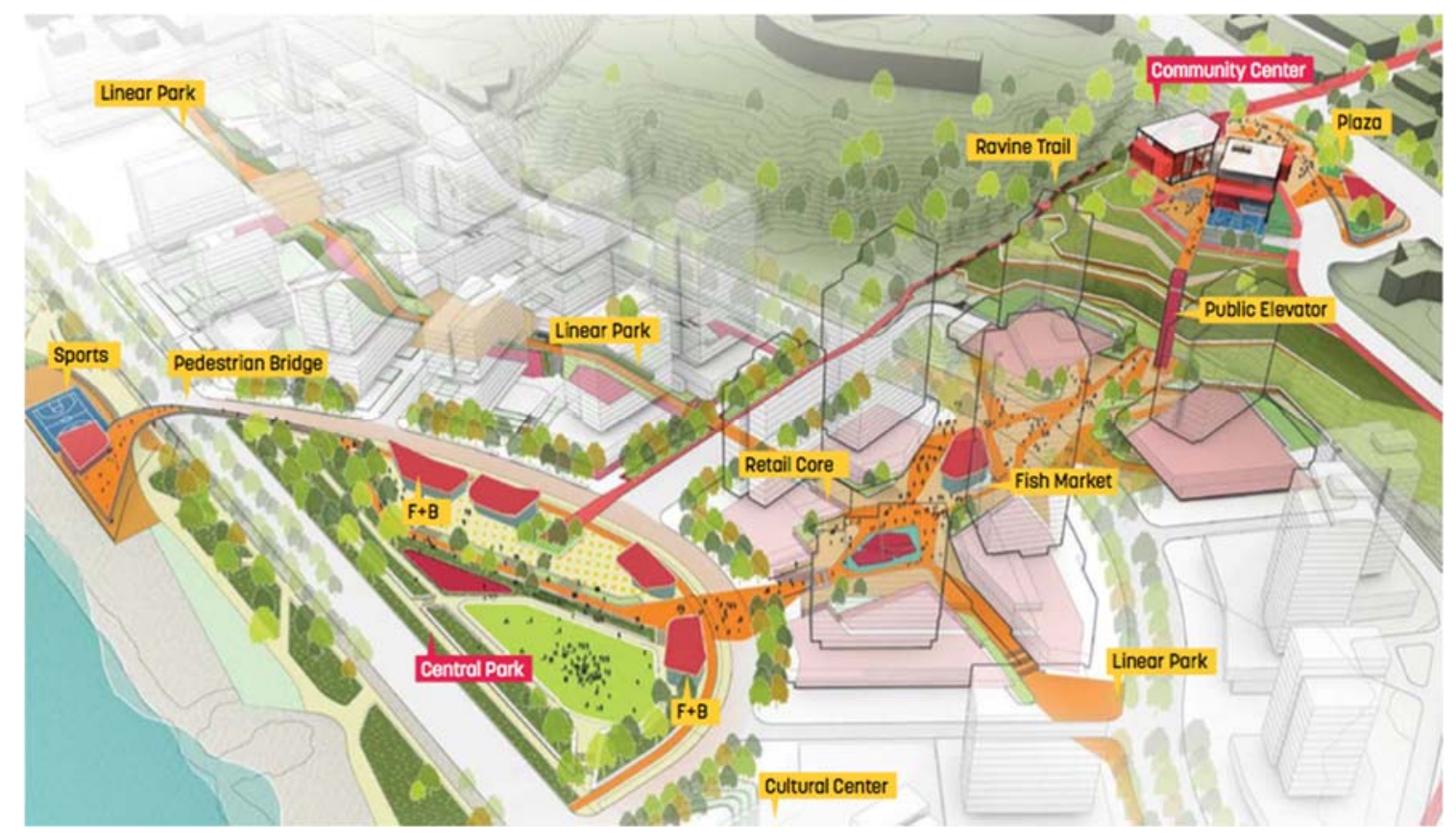

Figure 5. Site plan facilitating social connectivity within Las Salinas and to neighboring communities. Image courtesy of Sasaki.

In addition to ecological and social connections, the design for Las Salinas regenerates the complexity and health of the landscape in multiple ways. Stormwater is slowed and allowed to infiltrate the soil and recharge the aquifer using appropriate landscaping and design, pervious pavements, and the reuse of water $[67,68]$. Sediments are filtered through the landscape before reaching the sea. Spaces for social integration and interaction with nature (e.g., parks, boardwalks, beaches) are abundant [68].

Collaborations between regional stakeholders have already resulted in urban forestry and watershed regeneration initiatives, and more mutualistic relationships continue to emerge. Shifting from a conventional and transactional development and design proposal to a regenerative, reciprocal, and co-creative one has garnered the support of eighteen activist groups, including municipal planners who had initially opposed the development. It has integrated and built upon Las Salinas' LEED-ND certification to play a key role in manifesting the potential of Viña del Mar by working across scales to add value and manifest potential [67].

There is still a long way to go from the planning and remediation phases to construction and there is no guarantee that the regenerative direction of the project will continue. However, development and design team members are confident that the collaborative atmosphere they established during the planning process will continue through the construction phase and beyond. They feel that the energy field of will and caring that has been developed will continue to grow and evolve. They see this manifesting in the collaborative relationships which are forming in the community $[66,67]$. Regenesis Group's involvement in the Las Salinas project continues, focusing on the development and design team members' inner/personal development that is necessary to keep the project moving forward in a regenerative direction [67]. Further, team members understand that the project must keep evolving to stay relevant [66]. 
Box 1. Regenerative development outcomes and indicators in Las Salinas.

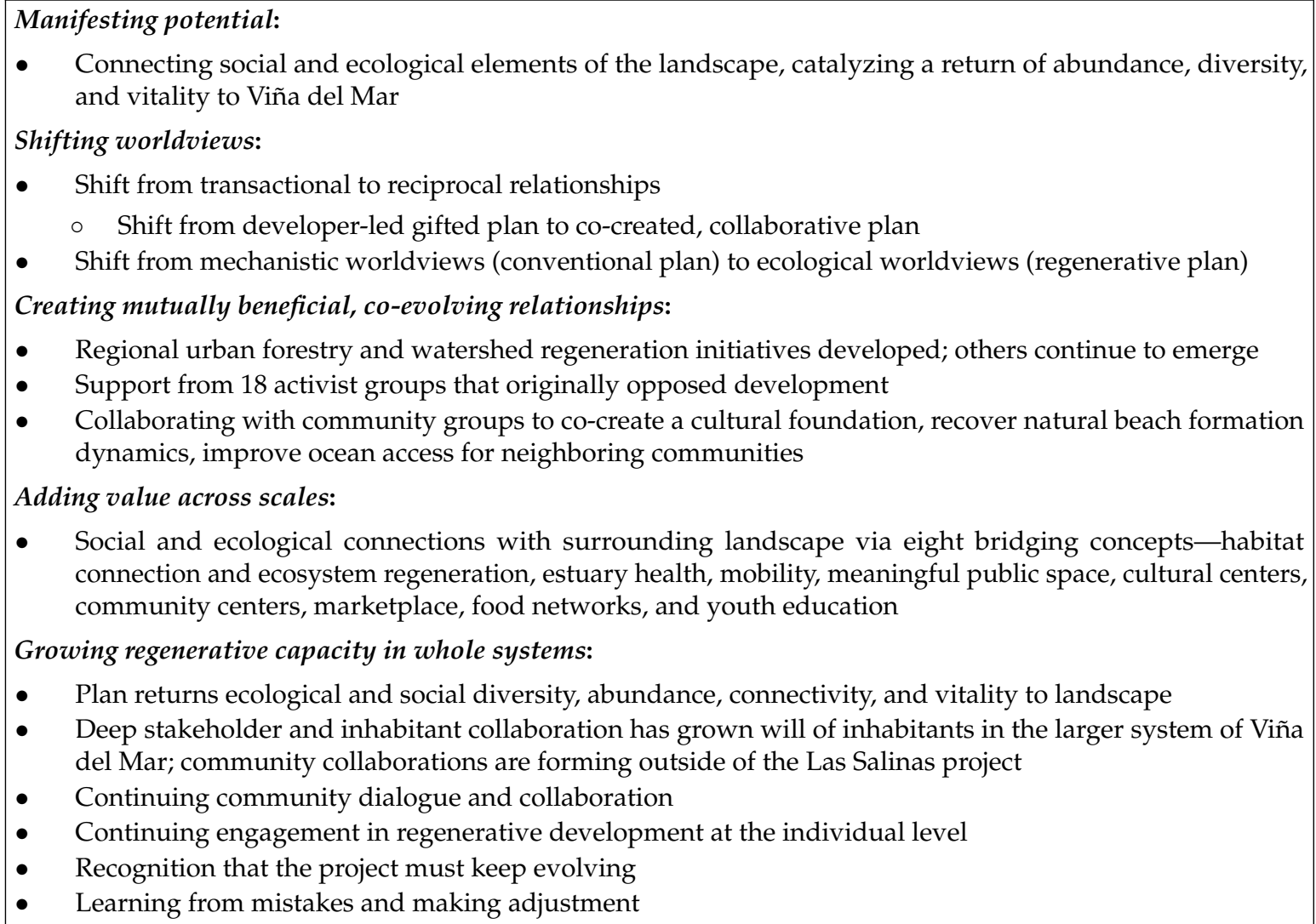

- Connecting social and ecological elements of the landscape, catalyzing a return of abundance, diversity, and vitality to Viña del Mar

\section{Shifting worldviews:}

- $\quad$ Shift from transactional to reciprocal relationships

- Shift from developer-led gifted plan to co-created, collaborative plan

- Shift from mechanistic worldviews (conventional plan) to ecological worldviews (regenerative plan)

Creating mutually beneficial, co-evolving relationships:

- $\quad$ Regional urban forestry and watershed regeneration initiatives developed; others continue to emerge

- Support from 18 activist groups that originally opposed development

- Collaborating with community groups to co-create a cultural foundation, recover natural beach formation dynamics, improve ocean access for neighboring communities

Adding value across scales:

- $\quad$ Social and ecological connections with surrounding landscape via eight bridging concepts-habitat connection and ecosystem regeneration, estuary health, mobility, meaningful public space, cultural centers, community centers, marketplace, food networks, and youth education

Growing regenerative capacity in whole systems:

- Plan returns ecological and social diversity, abundance, connectivity, and vitality to landscape

- Deep stakeholder and inhabitant collaboration has grown will of inhabitants in the larger system of Viña del Mar; community collaborations are forming outside of the Las Salinas project

- Continuing community dialogue and collaboration

- $\quad$ Continuing engagement in regenerative development at the individual level

- Recognition that the project must keep evolving

- $\quad$ Learning from mistakes and making adjustment

\subsection{Playa Viva, Juluchuca, Guerrero, Mexico}

Playa Viva is a 200-acre regenerative ecoresort in Juluchuca, Guerrero, Mexico (Figure 6). Playa Viva's developers and owners wanted the resort to be more than green or sustainable. They wanted it to improve not only the land it was on but also the surrounding landscape and community. From 2006-2007, Regenesis Group facilitated a process of discovery and co-creation from which emerged a regenerative direction for the resort, which opened in $2009[36,67,69]$. Playa Viva is a good example of a project that developed regenerative capacity and continues to evolve that capacity today (Box 2).

An integral assessment revealed that Playa Viva was once a small but important community that was part of a thriving regional population of 10,000 people [67]. As a result of the richness of the estuary, forest, and coast in this region, the community provided valuable goods to the surrounding areas. Deep listening and dialogue sessions with inhabitants revealed a story of abundance, dense biodiversity, trees bursting with fruit, lagoons overflowing with fish, and nature teaming with life [69]. In the 1920s, a large portion of the coastal landscape of the state of Guerrero was slashed and burned and turned into coconut monocultures, degenerating the former vitality and abundance of this place. Rapid discharge of water attributable to the loss of key vegetation led to shortages in water supplies for Juluchuca. Young residents were leaving the community in search of better economic opportunities and quality of life. The estuary was slowly degenerating into a marsh $[67,69]$. 
Box 2. Regenerative development outcomes and indicators in Playa Viva.

\section{Manifesting potential:}

- Abundance and vitality returning to landscape—estuary regeneration, community co-evolution, and transformational guest experiences

\section{Shifting worldviews:}

- Collaborative, reciprocal relationships

- Farmer trainings and products

- Salt and coconut businesses

- Ecotourism, turtle sanctuary

- Continually asking how to continue co-evolving with place

- Actions nourishing whole system health

Creating mutually beneficial, co-evolving relationships:

- Reciprocal economic relationships-Permaculture and biodynamic farmers, salt cooperative, coconut and ecotourism businesses

- Reciprocal humanitarian relationships-educational and health initiatives

- Reciprocal ecosystems relationships-coastal forests, mangroves, lagoon, watershed health, increasing biodiversity

- Initiatives continue to emerge and grow

- On-site development continues at rate that allows co-creation, feedback, and adjustment

Adding value across scales:

- Sponsoring education, health, and economic initiatives and support locally and regionally

- Estuary regeneration up and down coast

- Healthier watershed, agroecosystems, and livelihood opportunities for the community

- Increasing biodiversity

- Permaculture and biodynamic farmer trainings

- Replenishing aquifer

Growing regenerative capacity in whole systems:

- Beneficial initiatives continue to emerge and grow

- Increasing biodiversity through ecosystem restoration, resort Permaculture landscaping, upriver farming training that decreases toxic chemical inputs

- Ecosystem restoration:
- Estuary
- Mangrove swamps
- Coastal forests
- Lagoon

- Evolving thriving local living economies:

- Permaculture and biodynamic farmer trainings

- Local and international markets for farming products, coconut products, salt

- Ecotourism

- Guest investment in local businesses and initiatives

- Young people returning to area for good quality of life, livelihood opportunities 


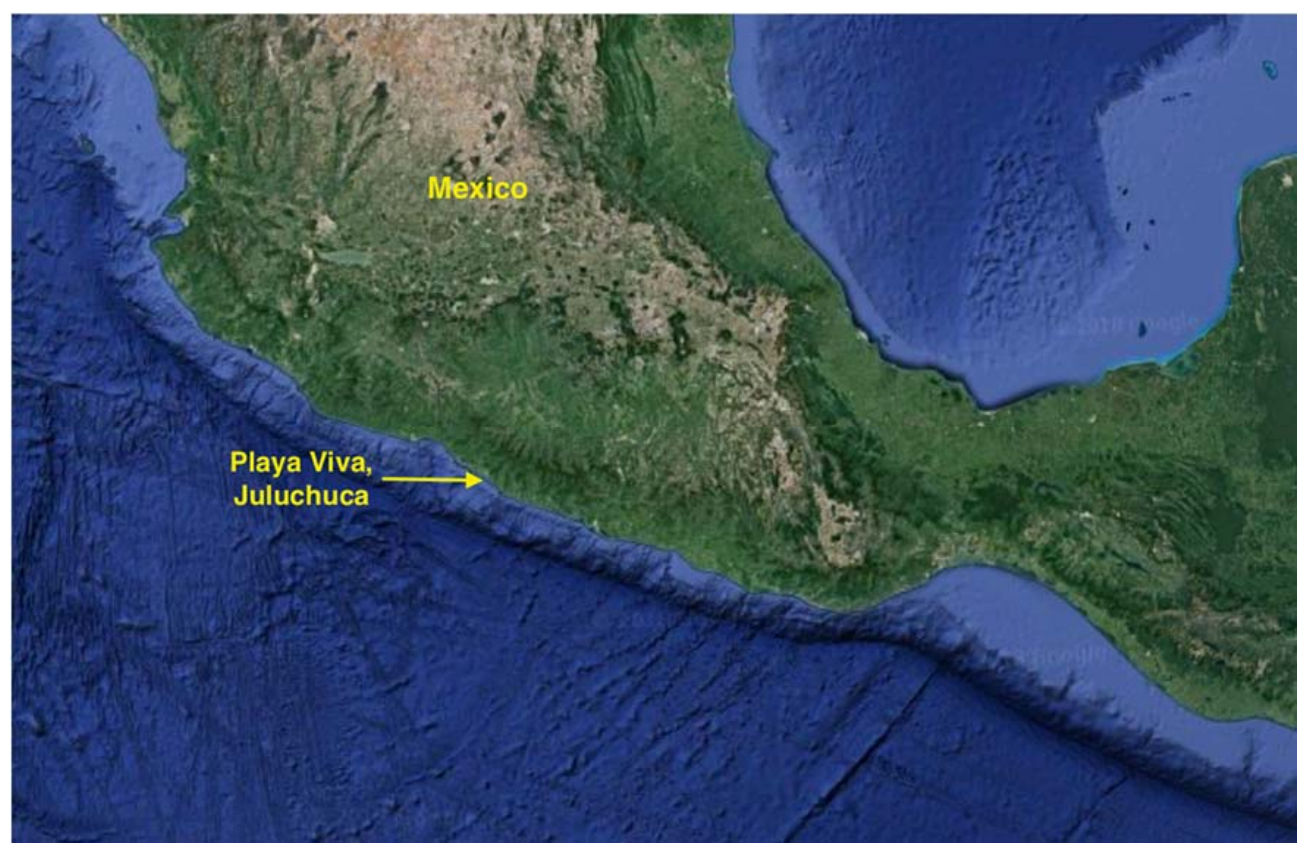

Figure 6. Playa Viva is located in Juluchuca, Guerrero, Mexico. Image adapted from Google Maps.

The regenerative concept that emerged for Playa Viva was that it could once again be a place of vitality and abundance, one that added value to the surrounding ecosystems, community of Juluchuca, and social-ecological systems further upstream. Playa Viva decided to focus on estuary regeneration, community co-evolution, and transformational guest experiences. Before Playa Viva began development on the land it owned, it began working with the community of Juluchuca as well as communities throughout the watershed to co-create and sponsor education, health, and economic development initiatives. These initiatives now offer guests of Playa Viva the opportunity to become deeply involved in community and ecosystem experiences, ones that they can continue to be involved in following their return home via investment in and growth of local businesses and initiatives [36].

Playa Viva began by establishing permaculture and biodynamic farming training programs for local farmers, helping to create a healthier watershed, agroecosystems, and livelihood opportunities for the community. Production expanded beyond the staple beans, corn, and squash to include fruits, vegetables, and tropical flowers. Playa Viva helped to create a community-supported agriculture cooperative for local farmers to have a market for their produce. The market has evolved and now includes a vibrant regional farmers' market [69].

Additionally, Playa Viva sponsored a detailed chemical analysis of this region's salt, leading to the discovery that this resource is distinctive, with desirable mineral content. The community sponsored a local fair trade cooperative that sells this unique salt to local resorts as well as internationally; this marks an evolution from previous methods, when visitors of the resort promoted the products by means of person-to-person marketing. Cooperative members continue to use traditional means of harvesting the salt, thus preserving ecosystem health and cultural heritage. Playa Viva also helped create a market for local coconut products and ecotourism. Further, it co-created and sponsors education and health initiatives that provide needed supplies for local schools and health clinics as well as English tutoring [69].

This holistic approach supports the local community with financial, intellectual, market, and social capital, creating local living economies. By engaging in a reciprocal relationship with these small industries through economic assistance, business training, access to resources, and access to markets, Playa Viva has helped increased their profitability and business viability. A supply and a demand for these activities has created a positive synergy between social and ecological components of this system and contributed to its vitality and abundance [69]. 
Playa Viva helped to develop a local turtle sanctuary that transformed poachers into turtle sanctuary employees and stewards. They collect and nurture turtle eggs as well as oversee the release of baby turtles into the wild. They have earned visibility and status within the community and now view themselves as defenders of indigenous turtles. They have become preservation experts and are important in the community's environmental regeneration. Additionally, Playa Viva is catalyzing the regeneration of estuaries along its borders, reviving a critical landscape element; it is also regenerating marine life, creating a carbon sink, improving local fisheries and water quality, stabilizing the land, and providing storm surge protection $[36,69]$.

Visitors to Playa Viva can participate in many of the above-mentioned activities, leading to friendships with villagers and investments in community businesses and initiatives [67]. Guests also pay a $2 \%$ Regenerative Trust fee that is directed to local environmental and community efforts [69]. These efforts have helped to increase economic opportunities, quality of life, and ecosystem health, drawing youth who now see a future here back to the community $[36,67]$.

Playa Viva is regenerating ecosystems on its own property as well. There is a 160-acre nature preserve where coastal forest biodiversity is undergoing regeneration through the planting of over 10,000 native trees. A once-thriving lagoon that dried up because of invasive cattle grass is being restored. Its biodiversity is increasing and Playa Viva plans to regenerate the entire lagoon. Playa Viva is slowly expanding its mangrove ecosystem through restoring and extending waterways that once thrived. The resort's permaculture-designed landscaping, which balances native, drought-tolerant, and aesthetic/food-bearing species, attracts birds and beneficial insects while serving as a living classroom for guests, local farmers, and WWOOFers (participants in World Wide Opportunities on Organic Farms) [69] (Figure 7).
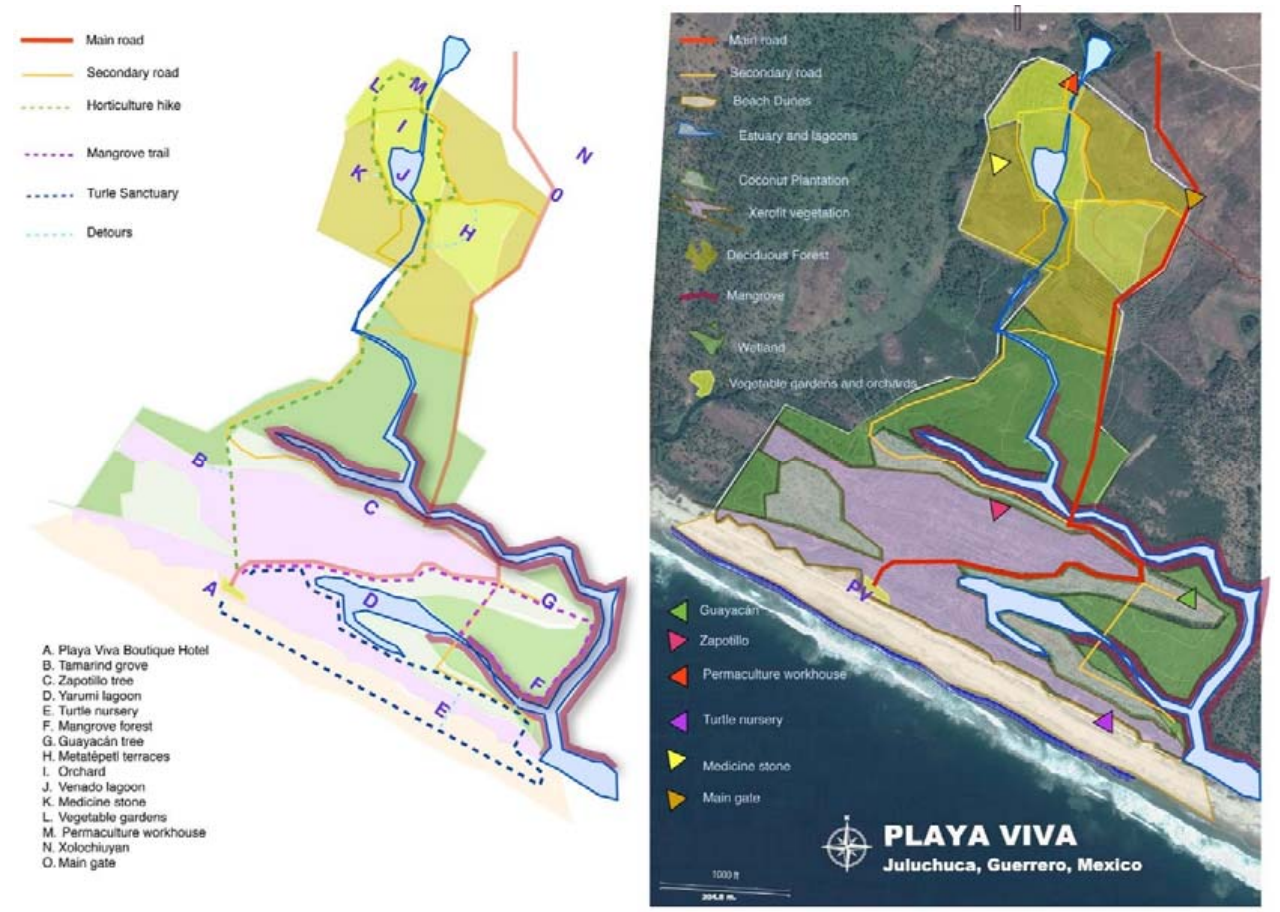

Figure 7. Land cover and use types present at Playa Viva. One hundred sixty of the 200 acres is a nature preserve. Playa Viva is regenerating the lagoon, mangrove forests, and coastal forests on its property as well as the estuary that connects to the broader landscape. Training in permaculture and biodynamic farming for regional farmers are helping to regenerate the landscape and ensure that the health of Playa Viva continues to increase. The turtle nursery has transformed poachers into ecosystem stewards. Image courtesy of Playa Viva. 
In terms of the built environment, Playa Viva is also replenishing the local aquifer by using grey water on gardens and mini-living systems for black water. Water is reused whenever possible and nutrients are extracted to enrich the soils. All energy production is solar and off-grid. Buildings are constructed of local, salvaged, and eco-friendly materials by local artisans, i.e., local craftspeople using traditional methods. They are designed according to natural cooling principles, with no need for air conditioning. Hotel materials (e.g., soaps, linens, dinnerware) and food are sourced both locally and on-site, where a wide variety of fruits, nuts, vegetables, seeds, chickens, and fish are available. As a reflection of Playa Viva's values of strong community, there is a balance of private and public spaces. Further, Playa Viva serves as a teaching model for local contractors and other resort owners in the area [69].

Playa Viva has continued its commitment to regeneration. It is allowing itself time to adapt and expand gradually in a co-evolving mutualism, receiving and responding to feedback from the community, ecosystem, and guests, with an increasingly beneficial effect on the surrounding community and ecosystems. Playa Viva continues to evolve because owners and employees are constantly reflecting on their value-adding role in this co-evolving living system, striving to be beneficial components. They demonstrate a commitment to place and to themselves as regenerative agents [67].

\section{Recommendations Moving Forward}

\subsection{Needs}

Several needs exist for advancing regenerative landscape development as a paradigm.

1. Conceptual and theoretical development.

Theoretical development should more fully integrate landscape sustainability science, design, and regenerative development. Scientific research and evidence can be developed to enhance current practices and vice versa.

2. Methodological frameworks.

Methodological frameworks should guide how design processes structure and integrate science, practice, knowledge, and action.

3. Assessment tools.

Assessment tools should move beyond typical prescriptive, fragmented, and deterministic checklists. Assessment tools can monitor dynamic change, developmental trajectories, and the on-going contribution of systems to the health and evolution of their larger wholes. Sociocultural and ecological processes and outcomes as well as their relationships can be assessed. To move toward sustainability, frameworks and assessment tools should allow for the flexibility, redundancy, and diversity found in living systems while also adequately addressing their complexity. They, and the humans using them, should begin to acknowledge that we cannot "solve" sustainability problems, but we can offer developmental pathways that can lead to greater health, vitality, and prosperity of the entire system [26]. Frameworks and assessments should be applied and adaptable across scales, with larger scales providing guidelines for approaches based in lower working levels and smaller scales providing the mechanisms driving higher-level processes [70]. Adaptive management and design experiments should be part of the strategies used to monitor and assess new and existing systems and projects $[8,40]$. Assessment tools should also be applicable to new as well as existing systems and be able to guide their development towards regenerative sustainability. Such a process requires an ongoing participatory and reflective process that nurtures social learning and is part of a culture of regenerative sustainability $[26,33,71]$.

4. Educational programs.

Educational programs for practitioners, students, scientists, stakeholders, and inhabitants of a place should teach the theory and practice of regenerative landscape development. 


\section{Implementation.}

Design experiments at all scales, including regional areas, dense urban areas, rural areas, neighborhoods, communities, building sites, and even households need to be conducted to inform policy and land use regulations $[3,7,9,25,59]$. Case studies on regenerative development and other regenerative sustainability projects can be conducted and used to create a portfolio of transdisciplinary working methods, frameworks, technologies, and assessments as well as their outcomes that may be adapted and used in different specific and local situations. Additionally, we must find the most effective methods for mechanistic approaches to enhance and inform approaches based on an ecological worldview to enable successful shifts toward regenerative sustainability. Policy, governance, power, and funding shifts reflecting this expanded paradigm and new knowledge will be key to implementation. Policy must make it not only possible to implement regenerative development but also desirable and, potentially, even required.

\subsection{Precautions}

Although regenerative development has tremendous potential as a transformational sustainability approach, it also faces challenges that could subvert it. For instance, we should be cautious of confusing regenerative development with regenerative design. If regenerative design is used in a larger context of a reductionistic paradigm, it will not result in systemic change; however, when used in the service of a guiding regenerative development process, systemic change towards regenerative sustainability could occur. Further, regenerative development has the potential to be "green washed," with the terms "regenerative development" and "regenerative design" used as marketing catch phrases, detached from their essential meaning. Similarly, regenerative development could be commandeered by powerful interests who use it to advance their self-serving agendas instead of increasing the health of whole living systems. Regenerative development is a reflexive process that identifies unintended consequences early and continuously, addressing distributional inequities or harm. Even if the essence and aims of regenerative development are followed, it is necessary to be attuned carefully to issues of equity, power, and governance, as these are particularly difficult components of social systems to transform.

It is also necessary to be aware of how the human ego may interact with regenerative development processes. There is inherent uncertainty in regenerative development because we cannot fully understand or predict the behavior or the future of the living systems of which we are a part. Additionally, the regenerative development process and its outcomes take time. It may be difficult for people to accept this uncertainty and maintain the patience necessary for the process to unfold. The natural impulse may be to implement too many changes, too quickly, and too broadly; conversely, the impulse may be to not implement the right kinds of changes or enough changes at the right scales and right points in the system. This can trigger degenerative instead of regenerative processes in living systems $[19,72]$.

We should be careful about when and how we use reductionistic methods in conjunction with ecological methods. We could become overly dismissive of mechanistic methods and tools, ceasing to recognize their usefulness or, conversely, we could become overly reliant on them. The same is true of quantitative versus qualitative methods. We should also be aware of our tendency to be uncomfortable with "failure", recognizing that a regenerative development approach requires an attitude of experimentation and learning as well as an openness to systems behaving in ways we cannot predict $[9,73,74]$. We should be mindful of our tendency to create things that are too fixed and not amenable to change, adaptation, and evolution. Further, we should be careful not to set processes in motion without monitoring them with capacity-building collaborative partnerships between inhabitants of a place, scientists, and stakeholders.

Regenerative development is not a natural practice for most people in the western world. We are steeped in a mechanistic worldview, and our default beliefs, thinking mechanisms, and actions emerge from there. Regenerative development ultimately grows from individuals who consciously commit to changing their own worldviews and ways of being in the world. This is no small task; it takes 
constant commitment and effort. Learning how to be a regenerative development practitioner or regenerative inhabitant of a living system is not easy. It is not as simple as implementing a formula or technologies or following a prescribed list of activities. It is as much an art as it is a science; it will take a complementary approach of both disciplines to move forward. It will take continual effort to create the commitment and caring necessary to continue on a regenerative pathway. It will take a new kind of practitioner who possesses new skills, mindsets, and aspirations and constantly nurtures these [19]. Initially, it may be difficult to find fully willing practitioners and to provide them with the training and support they need. Yet, it might just be the approach to regenerate humanity and all life beyond.

\section{Conclusions}

We have argued that regenerative development integrates sustainability, ecology, and design and fills gaps left by other transdicsiplinary frameworks. It elevates the aims and methodologies of sustainability science and practice to ones that build capacities in living systems to manifest increasingly higher levels of health, well-being, and happiness. It does this by intentionally holding and operating from an ecological worldview, simultaneously drawing on recent understandings in sustainability and ecology as well as the power of design as an integrating and transformational methodology.

Although landscape sustainability science aims to improve the relationship between humans and ecosystems in landscapes [1], collaborations toward this aim have been slow. We have proposed that regenerative development can provide a platform for a new sustainability paradigm for landscapes. This new paradigm - regenerative landscape development-integrates regenerative development with landscape sustainability science. It would (1) synthesize descriptive-analytical and transformational modes of sustainability science, (2) create necessary shifts in deeply held worldviews, (3) develop mutualistic human-nature relationships, (4) build regenerative capacities of living systems, and (5) manifest potential in living systems rather than focusing on problems from an anthropocentric, mechanistic worldview $[18,19,36,56]$.

The development of the regenerative landscape development paradigm will require conceptual and theoretical development, methodological frameworks, assessment tools, educational programs, and implementation coupled with experimentation. We must be careful not to green wash regenerative development, to be humble to its emergent processes, to appropriately integrate reductionistic methods with methods stemming from an ecological worldview, and to understand that this approach takes full commitment to personal change as well as to change in the systems of which we are a part. Despite these needs and precautions, regenerative landscape development has the potential to create a thriving and abundant future for all life $[18,19,25,26,36]$.

We argue that it is time to raise the aim of sustainability from improving the relationship between humans and ecosystems in landscapes to living in ways that nourish the perpetuation of well-being for all life in living systems. It is time to stop focusing on problems and instead focus on potential. It is time for humans to take responsibility for their co-creative role in the state of well-being of the living systems of which they are a part and live in ways that are full of purpose, meaning, and fulfillment. Regenerative development is a methodology that has been pursuing these aims for over 20 years [19]. By fully integrating landscape sustainability science with regenerative development in a new paradigm of regenerative landscape development, achieving these new aims for sustainability from local to global scales might just be possible. We invite you to be part of that process.

Author Contributions: L.V.G. led the collaborative efforts to produce this publication. All authors contributed substantially to the ideas, concepts, and work presented in this paper. All authors were also involved in the preparation of the manuscript and have approved the submitted form.

Acknowledgments: The authors wish to thank Regenesis Group, Sasaki, and Playa Viva for the time and images they generously gave in preparation of this manuscript.

Conflicts of Interest: The authors declare no conflict of interest. 


\section{References}

1. $\mathrm{Wu}, \mathrm{J}$. Landscape sustainability science: Ecosystem services and human well-being in changing landscapes. Landsc. Ecol. 2013, 28, 999-1023. [CrossRef]

2. Nassauer, J.I. Landscape as medium and method for synthesis in urban ecological design. Landsc. Urban Plan. 2012, 106, 221-229. [CrossRef]

3. Opdam, P.; Nassauer, J.I.; Wang, Z.; Albert, C.; Bentrup, G.; Castella, J.C.; McAlpine, C.; Liu, J.; Sheppard, S.; Swaffield, S. Science for action at the local landscape scale. Landsc. Ecol. 2013, 28, 1439-1445. [CrossRef]

4. Forman, R.T.T. Urban Regions: Ecology and Planning Beyond the City; Cambridge University Press: Cambridge, UK, 2008.

5. Wu, J.; Hobbs, R. Landscape ecology: The state-of-the-science. In Key Topics in Landscape Ecology; Wu, J., Hobbs, R.J., Eds.; Cambridge University Press: New York, NY, USA, 2007; pp. 271-287.

6. Nassauer, J.I.; Opdam, P. Design in science: Extending the landscape ecology paradigm. Landsc. Ecol. 2008, 23, 633-644. [CrossRef]

7. Childers, D.L.; Cadenasso, M.L.; Grove, J.M.; Marshall, V.; McGrath, B.; Pickett, S.T.A. An ecology for cities: A transformational nexus of design and ecology to advance climate change resilience and urban sustainability. Sustainability 2015, 7, 3774-3791. [CrossRef]

8. Felson, A.J.; Pickett, S.T.A. Designed experiments: New approaches to studying urban ecosystems. J. Ecol. Soc. Am. 2005, 3, 549-556. [CrossRef]

9. Felson, A.J.; Bradford, M.A.; Terway, T.M. Promoting Earth Stewardship through urban design experiments. Front. Ecol. Environ. 2013, 11, 362-367. [CrossRef]

10. Fischer, M. Design it! Solving sustainability problems by applying design thinking. GAIA 2015, 24, 174-178. [CrossRef]

11. Grove, J.M. Ecological and social linkages in urban design projects: A synthesis. In Resilience in Urban Ecology and Design: Linking Theory and Practice for Sustainable Cities; Pickett, S.T.A., Cadenasso, M.L., McGrath, B.P., Eds.; Springer: New York, NY, USA, 2013; pp. 211-230.

12. Barnosky, A.D.; Hadly, E.A.; Bascompte, J.; Berlow, E.L.; Brown, J.H.; Fortelius, M.; Getz, W.M.; Harte, J.; Hastings, A.; Marquet, P.A.; et al. Approaching a state shift in Earth's biosphere. Nature 2012, 486, 52-58. [CrossRef] [PubMed]

13. Sterman, J.D. Sustaining sustainability: Creating a systems science in a fragmented academy and polarized world. In Sustainability Science: The Emerging Paradigm and the Urban Environment; Weinstein, M.P., Turner, R.E., Eds.; Springer: New York, NY, USA, 2012; pp. 21-58.

14. Van der Leeuw, S.; Wiek, A.; Harlow, J.; Buizer, J. How much time do we have? Urgency and rhetoric in sustainability science. Sustain. Sci. 2012, 7 (Suppl. 1), 115-120. [CrossRef]

15. Thackara, J. In the Bubble: Designing for a Complex World; MIT Press: Cambridge, MA, USA, 2006.

16. Corral-Verdugo, V.; Frías-Armenta, M. The sustainability of positive environments. Environ. Dev. Sustain. 2016, 18, 965-984. [CrossRef]

17. Fry, T. Becoming Human by Design; Bloomsbury Publishing: New York, NY, USA, 2012.

18. Mang, P.; Reed, B. Designing from place: A regenerative framework and methodology. Build. Res. Inf. 2012, 40, 23-38. [CrossRef]

19. Mang, P.; Haggard, B.; Regenesis. Regenerative Development and Design: A Framework for Evolving Sustainability; John Wiley \& Sons, Inc.: Hoboken, NJ, USA, 2016.

20. Register, R. Ecocities: Building Cities in Balance with Nature; New Society Publishers: Gabriola Island, BC, Canada, 2006.

21. Kunstler, J.H. The City in Mind: Notes on the Urban Condition; Simon and Schuster, Inc.: New York, NY, USA, 2003.

22. Jacobs, J. The Death and Life of Great American Citie; Vintage Books: New York, NY, USA, 1961.

23. Innes, J.E.; Booher, D.E. Consensus building and complex adaptive systems: A framework for evaluating collaborative planning. J. Am. Plan. Assoc. 1999, 65, 412-423. [CrossRef]

24. Fischer, F. Climate Crisis and the Democratic Prospect: Participatory Governance in Sustainable Communities; Oxford University Press: Oxford, UK, 2017.

25. DuPlessis, C. Towards a regenerative paradigm for the built environment. Build. Res. Inf. 2012, 40, 7-22. [CrossRef] 
26. DuPlessis, C.; Brandon, P. An ecological paradigm as basis for a regenerative sustainability paradigm for the built environment. J. Clean. Prod. 2015, 109, 53-61. [CrossRef]

27. Abson, D.J.; Fischer, J.; Leventon, J.; Newig, J.; Schomerus, T.; Vilsmaier, U.; von Wehrden, H.; Abernethy, P.; Ives, C.D.; Jager, N.W.; et al. Leverage points for sustainability transformation. Ambio 2017, 46, 30-39. [CrossRef] [PubMed]

28. Meadows, D. Leverage Points: Places to Intervene in a System; The Sustainability Institute: Hartland, VT, USA, 1999.

29. Steiner, F. The Living Landscape: An Ecological Approach to Landscape Planning; McGraw Hill: New York, NY, USA, 2010.

30. Beatley, T.; Manning, K. The Ecology of Place: Planning for Environment, Economy, and Community; Island Press: Washington, DC, USA, 1997.

31. Steiner, F.; Simmons, M.; Gallagher, M.; Ranganathan, J.; Robertson, C. The ecological imperative for environmental design and planning. Front. Ecol. Environ. 2013, 11, 355-361. [CrossRef]

32. Van der Ryn, S.; Cowan, S. Ecological Design, 10th ed.; Island Press: Washington, DC, USA, 2007.

33. Wahl, D. Designing Regenerative Cultures; Triarchy Press: Axminster, UK, 2016.

34. Cohen, B. Urbanization in developing countries: Current trends, future projections, \& key challenges for sustainability. Technol. Soc. 2006, 28, 63-80.

35. Grose, M.J. Gaps and futures in working between ecology and design for constructed ecologies. Landsc. Urban Plan. 2014, 132, 69-78. [CrossRef]

36. Benne, B.; Mang, P. Working regeneratively across scales-Insights from nature applied to the built environment. J. Clean. Prod. 2015, 109, 42-52. [CrossRef]

37. Cross, N. Designerly ways of knowing. Des. Stud. 1982, 3, 221-227. [CrossRef]

38. Jasanoff, S. Designs on Nature: Science and Democracy in Europe and the United States; Princeton University Press: Princeton, NJ, USA, 2005.

39. Miller, T.D. Constructing sustainability science: Emerging perspectives and research trajectories. Sustain. Sci. 2013, 8, 279-293. [CrossRef]

40. Musacchio, L.R. The scientific basis for the design of landscape sustainability: A conceptual framework for translational landscape research and practice of designed landscapes and the six E's of landscape sustainability. Landsc. Ecol. 2009, 24, 993-1013. [CrossRef]

41. Westley, F.; Olsson, P.; Folke, C.; Homer-Dixon, T.; Vredenburg, H.; Loorbcah, D.; Thompson, J.; Nilsson, M.; Lambin, E.; Sendzimir, J.; et al. Tipping toward sustainability: Emerging pathways of transformation. Ambio 2011, 40, 762-780. [CrossRef] [PubMed]

42. Fischer, J.; Dyball, R.; Fazey, I.; Gross, C.; Dovers, S.; Ehrlich, P.R.; Brulle, R.J.; Christensen, C.; Borden, R.J. Human behavior and sustainability. Front. Ecol. Environ. 2012, 10, 153-160. [CrossRef]

43. Ahern, J. Urban landscape sustainability and resilience: The promise and challenges of integrating ecology with urban planning and design. Landsc. Ecol. 2013, 28, 1203-1212. [CrossRef]

44. Ahern, J.; Cilliers, S.; Niemelä, J. The concept of ecosystem services in adaptive urban planning and design: A framework for supporting innovation. Landsc. Urban Plan. 2014, 125, 254-259. [CrossRef]

45. Lovell, S.T.; Johnston, D.M. Creating multifunctional landscapes: How can the field of ecology inform the design of the landscape? Front. Ecol. Environ. 2009, 7, 212-220. [CrossRef]

46. Lovell, S.T.; Taylor, J.R. Supplying urban ecosystem services through multifunctional green infrastructure in the United States. Landsc. Ecol. 2013, 28, 1447-1463. [CrossRef]

47. Musacchio, L.R. The grand challenge to operationalize landscape sustainability and the design-in-science paradigm. Landsc. Ecol. 2011, 26, 1-5. [CrossRef]

48. Pickett, S.T.A.; Cadenasso, M.L.; McGrath, B. Resilience in Ecology and Urban Design: Linking Theory and Practice for Sustainable Cities; Springer: New York, NY, USA, 2013.

49. Picket, S.T.A.; Boone, C.G.; McGrath, B.; Cadenasso, M.L.; Childers, D.L.; Ogden, L.A.; McHale, M.; Grove, M. Ecological science and transformation to the sustainable city. Cities 2013, 32, S10-S20. [CrossRef]

50. Wu, J. Key concepts and research topics in landscape ecology revisited: 30 years after the Allerton Park workshop. Landsc. Ecol. 2013, 20,1-11. [CrossRef]

51. Orr, D. The Nature of Design-Ecology, Culture, and Human Intention; Oxford University Press: Oxford, UK, 2002.

52. Musacchio, L.R. Cultivating deep care: Integrating landscape ecological research into the cultural dimensions of ecosystem services. Landsc. Ecol. 2013, 28, 1025-1038. [CrossRef] 
53. Naveh, Z. Landscape ecology and sustainability. Landsc. Ecol. 2007, 22, 1437-1440. [CrossRef]

54. $\mathrm{Wu}, \mathrm{J}$. Landscape of culture and culture of landscape: Does landscape ecology need culture? Landsc. Ecol. 2010, 25, 1147-1150. [CrossRef]

55. Wu, J. Urban ecology and sustainability: The state-of-the-science and future directions. Landsc. Urban Plan. 2014, 125, 209-221. [CrossRef]

56. Reed, B. Shifting from 'sustainability' to regeneration. Build. Res. Inf. 2007, 35, 674-680. [CrossRef]

57. Kopnina, H. The victims of unsustainability: A challenge to sustainable development goals. Int. J. Sustain. Dev. World 2015. [CrossRef]

58. Hes, D.; duPlessis, C. Designing for Hope: Pathways to Regenerative Sustainability; Routledge: New York, NY, USA, 2015.

59. Cole, R.J. Regenerative design and development: Current theory and practice. Build. Res. Inf. 2012, 40, 1-6. [CrossRef]

60. Viganò, P. Urbanism and ecological rationality. In Resilience in Urban Ecology and Design: Linking Theory and Practice for Sustainable Cities; Pickett, S.T.A., Cadenasso, M.L., McGrath, B.P., Eds.; Springer: New York, NY, USA, 2013; pp. 407-426.

61. Plaut, J.; (Institute for the Built Environment, Colorado State University, Fort Collins, CO, USA). Personal communication, 2017.

62. Mang, P.; (Regenesis Group, Santa Fe, New Mexico, USA). Personal communication, 2016.

63. Cloudburst; The Commonwealth. The Commonwealth and Cloudburst's Workshop on Regenerative Development to Reverse Climate Change; Cloudburst: London, UK; The Commonwealth: London, UK, 2016.

64. World Future Council, Climate, Energy, and Cities. Available online: https://www.worldfuturecouncil.org/ climate-energy-and-cities/ (accessed on 28 March 2018).

65. Plaut, J.M.; Dunbar, B.; Wackerman, A.; Hodgin, S. Regenerative design: The LENSES framework for buildings and communities. Build. Res. Inf. 2012, 40, 112-122. [CrossRef]

66. Hennick, C. Sustainable Chile. In USGBC+, Transforming Our Built Environment; USGBC: Washington, DC, USA, 2018; pp. 38-47.

67. Reed, B. (Regenesis Group, Boston, NY, USA). Personal communication, 2018.

68. Sasaki, Las Salinas. Available online: http://www.sasaki.com/project/421/las-salinas/ (accessed on 11 May 2018).

69. Playa Viva. Available online: http:/ / www.playaviva.com (accessed on 7 May 2018).

70. Wu, J.; Loucks, O.L. From balance of nature to hierarchical patch dynamics: A paradigm shift in ecology. Q. Rev. Biol. 1995, 70, 439-466. [CrossRef]

71. Reed, M.S.; Evely, A.C.; Cundill, G.; Fazey, I.; Glass, J.; Laing, A.; Newig, J.; Parrish, B.; Prell, C.; Raymond, C.; et al. What is social learning? Ecol. Soc. 2010, 15, r1. [CrossRef]

72. Gunderson, L.H.; Holling, C.S. Panarchy: Understanding Transformations in Human and Natural Systems; Island Press: Washington, DC, USA, 2002.

73. Ahern, J. From fail-safe to safe-to-fail: Sustainability and resilience in the new urban world. Landsc. Urban Plan. 2011, 100, 341-343. [CrossRef]

74. Holling, C.S. From complex regions to complex worlds. Ecol. Soc. 2004, 9, 11. [CrossRef]

(C) 2018 by the authors. Licensee MDPI, Basel, Switzerland. This article is an open access article distributed under the terms and conditions of the Creative Commons Attribution (CC BY) license (http://creativecommons.org/licenses/by/4.0/). 